DOI: $10.17805 / z p u .2017 .2 .16$

\title{
Половая мораль московских студентов: религиозный аспект
}

\author{
Д. А. ТИХОМИРОВ \\ РОССИЙСКИЙ ЭКОНОМИЧЕСКИЙ УНИВЕРСИТЕТ ИМ. Г. В. ПЛЕХАНОВА
}

В статье на основании результатов проведенного автором в 2016 г. эмпирического исследования рассматривается влияние религии на семейно-брачные ценности и нормы московских студентов, причисляющих себя к последователям той или иной религии. Проводится дифференциация отношения религиозных (православных и мусульман), нерелигиозных и неверующих студентов к многодетности, добрачному целомудрию, сожительству, разводу, супружеским изменам, однополым бракам. Восприятие этих явлений различается как между религиозными, нерелигиозными и неверующими группами, так и внутри религиозной группы. Наиболее выражены традиционные взгляды на семью и половую мораль у религиозных студентов, наименее - у неверующих. Среди религиозных студентов мусульмане занимают более традиционную позицию в вопросах половой морали, нежели православные, за исключением группы воцерковленных, но ее численность незначительна (4\% от всех православных). Автор показывает, что отношение к обозначенным выше аспектам семейно-брачной сферы как норме или отклонению определяется не только религиозной принадлежностью, но и уровнем религиозности молодежи. Однако в целом для православных, хотя и в гораздо меньшей степени, чем для нерелигиозных и неверующих студентов, характерна деструкция нормативности в различных вопросах половой морали.

Либерализация половой морали в России практически не затронула сферу нетрадиционных сексуальных отношений. Большинство московских студентов, особенно религиозных, воспринимают однополую любовь как ярко выраженное отклонение.

Ключевые слова: половая мораль; религиозность; православные; мусульмане; студенты; ценности; целомудрие; сожительство; однополые браки 


\section{BВЕАЕНИЕ}

и иберализация половой морали, развертывающаяся в России с конца XX в., размы$\mathcal{1}$ вает культурные традиции, ценности и нормы, призванные регулировать социальные отношения в семейно-брачной сфере. Аеструкция нормативности в вопросах половой морали, хотя и с различной интенсивностью, происходит, как показывают наши исследования, во всех возрастных группах (Ауков, Тихомиров, 2012). Аругими словами, старшие поколения уже не являются однозначными носителями социальных норм в сфере взаимоотношения полов.

Но об окончательном распаде ценностно-нормативной системы говорить пока преждевременно. Постоянный риск сползания в демографическую яму фокусирует внимание общества на семейно-брачной проблематике. Все чаще высшими органами государственной власти артикулируется необходимость воссоздания традиционных семейно-брачных ценностей (например, в Концепции государственной семейной политики в Российской Федерации на период до 2025 года (Указ Президента ... , 2007: Электронный ресурс; Концепция ..., , 2014: Электронный ресурс). Идут поиски ценностных основ для формирования национально-культурной идентичности. Связующим звеном этой конструкции могут стать православие и другие традиционные религии России, возрождение которых происходит на фоне либерализации половой морали. Интерес к вере в различных социальных группах российского общества (включая и студенческую молодежь), сопровождающийся высокими количественными показателями самоидентификации с той или иной религией, несмотря на переход к информационному обществу, сохраняется. В этой связи возникает вопрос: влияет ли религия на семейно-брачные ценности и нормы студентов, причисляющих себя к последователям той или иной религии или же деструкция нормативности в вопросах половой морали характерна и для них? В раскрытии данной темы видится и цель этой статьи.

Определенный материал для прояснения поставленной проблемы дает проведенное автором в конце 2016 г. эмпирическое исследование среди московских студентов гуманитарного профиля относительно влияния уровня и степени их религиозности на ценности, нормы и установки в сфере семейно-брачных отношений. В качестве метода исследования было использовано анкетирование $(\mathrm{N}=605$, выборка квотная по полу и возрасту), соотношение полов здесь особенно важно, оно было максимально приближено к московской ситуации (среди опрошенных 64\% девушек и 36\% юношей, что соответствует распределению студентов в целом по столице).

\section{РЕАИГИОЗНОСТЬ МОСКОВСКИХ СТУАЕНТОВ}

Больше половины (56\%) опрошенных студентов считают себя религиозными людьми $(59 \%$ юношей и 54\% девушек) (верят в Бога и принадлежат к определенной религии), а еще 24\% верят в Бога или какие-либо высшие силы, но не идентифицируют себя с конкретной религией и не соблюдают религиозные обряды $(18 \%$ юношей и $27 \%$ девушек). Мы назвали первую группу «религиозными» студентами, а вторую «нерелигиозными», отметив, что только 15\% молодых людей отнесли себя к неверующим (17\% юношей и $14 \%$ девушек), а $5 \%$ пока окончательно не определились (6\% юношей и 5\% девушек). Среди религиозных студентов (56\% опрошенных) православными назвали себя 79\% (78\% юношей и 80\% девушек), мусульманами - 12\% (14\% юношей и $11 \%$ девушек), христианами Апостольской армянской церкви - 5\% (6\% юношей и 4\% девушек), буддистами - 3\% (1\% юношей и 4\% девушек) и др. 
Отношение молодежи к религии и специфика их поведения определяется их религиозной принадлежностью: наиболее выражена религиозность у мусульман, наименее - у православных христиан. Религия пока слабо влияет на образ жизни молодых людей, называющих себя православными, и она не стала частью их повседневной жизни. Регулярно соблюдающих религиозные обряды (посещение церкви, исповедь, причастие, молитва, чтение священных книг, пост) очень немного - всего несколько процентов. Если классифицировать православных верующих по степени интенсивности их религиозных практик, используя для этого разработанный В. Ф. Чесноковой индекс воцерковленности (Чеснокова, 2005), то четко выделяются четыре основные группы: воцерковленные - 4\%, полувоцерковленные - 19\%, слабо воцерковленные $-54 \%$, невоцерковленные - 24\% (Тихомиров, 2017).

\section{ЦЕННОСТНЫЕ УСТАНОВКИ СТУАЕНТОВ}

Основной ценностной установкой различных социальных групп студентов является семья. Так, 69\% респондентов отметили, что наиболее важной целью в жизни для них является создание хорошей семьи; совершенствоваться (духовно, интеллектуально, нравственно и др.) важно для 45\% опрошенных; иметь материальное благополучие - для 36\%; воспитать детей честными и порядочными людьми - для 35\%; быть здоровым - для 32\%, жить в свое удовольствие - для 22\%, путешествовать - для $22 \%$ респондентов. Просемейная направленность ценностных установок наиболее выражена у религиозных студентов, наименее - у неверующих. Создание хорошей семьи в качестве наиболее важной жизненной цели обозначили 78\% православных, 72\% мусульман, 57\% нерелигиозных и 48\% неверующих, а стремление к совершенствованию отметили 41\% православных, 48\% мусульман, 54\% нерелигиозных и 43\% неверующих.

В ценностных установках нерелигиозных и неверующих респондентов семье составляют активную конкуренцию другие жизненные приоритеты. Помимо совершенствования, можно выделить желание жить в свое удовольствие (33\%), путешествовать $(30 \%)$, иметь интересную работу (26\%), что значительно (в полтора-два раза) отличается от взглядов религиозных студентов.

\section{ОТНОШЕНИЕ К МНОГОАЕТНОСТИ}

Большинство опрошенных студентов отметили создание семьи как наиболее важную жизненную цель, однако в их представлении семья характеризуется малодетностью. Более половины не считают, что в семье должно быть много детей (скорее не важно - 33\%, совсем не важно - 21\%). Установку на многодетность в той или иной степени выражают треть респондентов (скорее важно - 25\%, очень важно - 7\%). В этом вопросе проявились значительные гендерные различия. Так, многодетность представляется важной для 44\% юношей (очень важной - 9\%) и только для 24\% девушек (очень важной $-5 \%$ ).

Отношение к многодетности определяется и религиозной принадлежностью. Важной многодетность считают 51\% мусульман (очень важной - 10\%), 36\% православных $(8 \%), 14 \%$ нерелигиозных $(1 \%)$ и $22 \%$ неверующих (2\%) студентов. Мусульмане придерживаются более традиционных взглядов по сравнению с другими группами студентов, в том числе и православных, за исключением группы воцерковленных (многодетность является важной для 80\% исповедующихся и причащающихся один раз в неделю и для 60\% совершающих эти таинства один раз в месяц). Обратим внимание, что ярко выраженная установка на многодетность сформирована только у каждого 
десятого религиозного респондента, преимущественно у мужчин, отличающихся наибольшей религиозностью.

\section{ОТНОШЕНИЕ КАОБРАЧНОМУ ЦЕАОМУАРИЮ}

Создание семьи является важной ценностной установкой среди московского студенчества, но представления о браке и добрачном поведении значительно меняются. Аиберализация половой морали привела к тому, что добрачные сексуальные отношения в современной России стали носить массовый характер (подробнее см. работы И. С. Кона, С. И. Голода, М. Б. Аенисенко и др.) и получили, по сути, одобрение со стороны общественного мнения.

Покажем эту трансформацию на примере трех опросов ВЦИОМ, охватывающих последнюю четверть века. В 1992 г. добрачные связи признали нормальными, допустимыми $37 \%$ россиян, а 41\% придерживались противоположного мнения (Кон, 2005). В 2000 г. 36\% респондентов заявили, что добрачная сексуальная жизнь аморальна, тогда как 55\% признали ее вполне нормальной (О семье ... , 2000: Электронный ресурс). В 2015 г. 21\% респондентов считали недопустимыми добрачные сексуальные отношения для юношей (среди 18-24-летних - 8\%, среди 25-34-летних - 11\%), для девушек - 26\% (среди 18-24-летних - 16\%, среди 25-34-летних - 15\%) (Аобрачный ..., 2015: Электронный ресурс).

Традиционная для русской культуры установка на добрачное целомудрие утратила свое былое значение, но не исчезла вовсе. Опрос студентов показал, что сохранение добрачного целомудрия представляется важным для $34 \%$ респондентов, противоположного мнения придерживаются 54\%. Половозрастные характеристики не проявили определяющего влияния на дифференциацию восприятия добрачного целомудрия как социальной нормы или отклонения. Большинство юношей и девушек отметили, что сохранение девственности до брака не является для них важным. Вместе с тем серьезные половозрастные различия проявились среди юношей в возрастной группе 20-24-летних. Так, если в группе 17-19-летних добрачное целомудрие представляется важным для 40\% юношей и $35 \%$ девушек, то в группе 20-24-летних - для $15 \%$ юношей и $32 \%$ девушек.

Аифференциация отношения студентов к добрачному целомудрию как социальной норме или отклонению главным образом определяется их религиозной принадлежностью. Отношение к добрачному целомудрию среди всего массива религиозных студентов противоречивое: $46 \%$ полагают, что девственность важна, а $42 \%$ придерживаются противоположного мнения. Значительные отличия высветились в отношении к добрачному целомудрию не только между религиозными, нерелигиозными и неверующими студентами, но и между различными религиозными группами. Наиболее четкую позицию в восприятии девственности как социальной нормы проявляют мусульмане, наименее четкую - православные. Аобрачное целомудрие важно для 72\% мусульман и только для $36 \%$ православных (см. табл. 1, с. 214). Во многом это объясняется более сильным влиянием ислама на образ жизни мусульман и формирование их ценностей, норм и установок. В целом уровень религиозности мусульман выше, нежели православных. Именно степень религиозности молодых православных и определяет их восприятие добрачного целомудрия: в качестве однозначной нормы для воцерковленных и отклонения для слабо воцерковленных (номинально верующих), которых, как показало наше исследование, пока большинство. Так, среди тех, кто исповедуется и причащается один раз в неделю, важно сохранение невинности до брака 
ОТНОШЕНИЕ СТУАЕНТОВ К АОБРАЧНОМУ ЦЕ ОМУАРИЮ

В ЗАВИСИМОСТИ ОТ ИХ РЕАИГИОЗНОЙ ПРИНАААЕЖНОСТИ, \%

Table 1

THE ATTITUDE OF STUDENTS TO PREMARITAL CHASTITY DEPENDING ON THEIR RELIGION, IN \%

\begin{tabular}{|l|c|c|c|c|}
\hline \multirow{2}{*}{$\begin{array}{c}\text { Важно ли сохранение } \\
\text { добрачного челомудрия? }\end{array}$} & \multicolumn{4}{|c|}{ Религиозная принадлежность } \\
\cline { 2 - 5 } & православнье & мусульмане & нерелигиозные & атеисть \\
\hline Очень важно & 10 & 31 & 6 & 4 \\
Скорее важно & 26 & 41 & 13 & 11 \\
Скорее не важно & 31 & 14 & 34 & 33 \\
Совсем не важно & 21 & - & 35 & 44 \\
Трудно сказать & 13 & 14 & 12 & 7 \\
\hline
\end{tabular}

Аля 100\%, один раз в месяц - для $60 \%$, несколько раз в год - для 44\%, в исключительных случаях - для $34 \%$, никогда - для $26 \%$.

\section{ОТНОШЕНИЕ КАОБРАЧНОМУ СОЖИТЕАЬСТВУ}

Еще более лояльно студенты относятся к сожительству вне брака. Аиберализация половой морали привела к переформатированию семейно-брачных отношений. Незарегистрированные супружеские союзы, особенно предшествующие официальному браку, стали социальной нормой, что проявляется как в одобрении этих отношений общественным мнением, так и в их широком распространении. По данным переписи населения 2010 г., число незарегистрированных супружеских союзов составило 13\% от всех браков (в 2002 г. - 9,7\%) (Вот какие мы ..., 2011: Электронный ресурс). Спустя пять лет, как показывают данные микропереписи населения 2015 г., ситуация практически не изменилась (12,4\% от всех браков) (Микроперепись ..., 2015: Электронный ресурс). Мониторинговое исследование Фонда общественного мнения (ФОМ) показывает, что число состоящих в браке россиян, имеющих опыт совместного проживания и ведения хозяйства до заключения официального брака, возросло в период 2004-2013 гг. с 21 до 29\%. Этот прирост произошел главным образом за счет молодежи: среди 18-30-летних 55\% начали жить вместе еще до регистрации брака (среди 31-45-летних - 39\%, среди 46-60-летних - 17\%, среди тех, кому за 60 лет, - 10\%) (Осипова, 2013: Электронный ресурс).

Значительные изменения брачного поведения находят отражение в общественном мнении. Согласно опросу ВЦИОМ 2014 г., сожительство вне брака считают недопустимым только 16\% россиян, тогда как противоположного мнения придерживаются 81\% (Брак, ..., 2015: Электронный ресурс).

Наши исследования (Тихомиров, 2009; Ауков, Тихомиров, 2012), проведенные в 2009-2010 гг., показали, что большинство молодых людей наиболее предпочтительным вариантом организации своей брачной жизни считали добрачное сожительство, рассматривая его как пробный брак.

Опрос 2016 г. продемонстрировал закрепление в восприятии студентов сожительства в качестве социальной нормы, в том числе среди респондентов, назвавших себя православными. Только каждый пятый опрошенный считает такую форму брачной организации неприемлемой (вступление в брак без практики добрачного сожительства 
представляется очень важным для 8\%, скорее важным - для 13\%), противоположной позиции придерживаются 71\% респондентов (скорее не важно - 22\%, совсем не важно - 49\%). В данном случае религиозный фактор не оказывает значимого влияния на дифференциацию восприятия сожительства как социальной нормы или отклонения между различными социальными группами (табл. 2). Тем не менее для большей части мусульман остается важным вступление в брак без практики добрачного сожительства, так же как и для воцерковленных христиан (для 80\% исповедующихся и причащающихся один раз в неделю и для 60\% совершающих эти таинства один раз в месяц).

Широкое распространение сожительств в России и одобрение их общественным мнением во многом является следствием нестабильности института брака.

\section{ОТНОШЕНИЕ К РАЗВОАУ}

Развод в России стал социальной нормой, подтверждением чему служат данные как официальной статистики о расторжении более половины браков - 52,7\% в 2015 г. (Россия, 2016), так и социологических исследований, фиксирующих лояльное отношение к нему в массовом сознании. Согласно опросу ФОМ 2012 г., большинство россиян считают разводы допустимыми, даже если в семье есть несовершеннолетний ребенок, и только 21\% респондентов убеждены, что разводы недопустимы ни при каких обстоятельствах (О разводах ..., 2013: Электронный ресурс). По данным опроса ВЦИОМ 2015 г., большинство россиян признают разводы допустимыми, противоположного мнения придерживаются только 11\% респондентов (О разводах ... , 2015: Электронный ресурс).

Отношение к разводу в студенческой среде менее либеральное, что во многом объясняется юношеским романтизмом и отсутствием жизненного опыта. В нашем исследовании большинство (51\%) молодых людей заявили о важности нерасторжимости брака, противоположной позиции придерживаются 40\%, а еще $9 \%$ окончательно не определились. Восприятие развода как социальной нормы или отклонения определяется религиозной принадлежностью. Неверующие и нерелигиозные студенты рассматривают развод как норму, религиозные - как отклонение. Так, допустимыми разводы считают 25\% мусульман, 34\% православных, 53\% нерелигиозных и 60\% неверующих студентов, а недопустимыми - 65\% мусульман, 57\% православных, 38\% нерелигиозных

Таблица 2

ОТНОШЕНИЕ СТУАЕНТОВ К АОБРАЧНОМУ СОЖИТЕАЬСТВУ В ЗАВИСИМОСТИ ОТ ИХ РЕАИГИОЗНОЙ ПРИНААИЕЖНОСТИ, \%

Table 2

THE ATTITUDE OF STUDENTS TO PREMARITAL COHABITATION DEPENDING ON THEIR RELIGION, IN \%

\begin{tabular}{|l|c|c|c|c|}
\hline \multirow{2}{*}{$\begin{array}{c}\text { Важно ли вступление } \\
\text { в брак без практики } \\
\text { сожительства? }\end{array}$} & \multicolumn{3}{|c|}{ Религиозная принадлежность } \\
\cline { 2 - 5 } & православнье & мусульлане & нерелигиознье & атеисть \\
\hline Очень важно & 8 & 17 & 3 & 2 \\
Скорее важно & 14 & 31 & 4 & 11 \\
Скорее не важно & 30 & 17 & 13 & 9 \\
Совсем не важно & 40 & 21 & 75 & 69 \\
Трудно сказать & 8 & 14 & 4 & 9 \\
\hline
\end{tabular}


и 33\% неверующих студентов. Мусульмане и по вопросу о допустимости развода занимают более традиционную позицию, нежели православные, за исключением опять же группы воцерковленных христиан (развод является недопустимым для 100\% исповедующихся и причащающихся один раз в неделю и для 67\% совершающих эти таинства один раз в месяц). Однако в данном случае их взгляды не настолько сильно отличаются, как в вопросах о добрачных сексуальных отношениях.

Одной из основных причин развода, по мнению россиян, является супружеская измена (там же). По данным опроса ВЦИОМ 2016 г., супружеские измены осуждают $71 \%$ респондентов (75\% среди 18-24-летних), а 20\% относятся к ним снисходительно (Навстречу ..., 2016: Электронный ресурс). Схожие результаты были получены да-центром в 2015 г.: согласно им супружеская измена воспринимается в качестве социальной нормы для 24\% респондентов, отклонения - 63\%. Причем для мужчин $(34 \%$ против $16 \%$ среди женщин) и для представителей молодого поколения (30\% среди 18-24-летних, 17\% среди тех, кому 55 лет и старше) в гораздо большей степени характерно относить такое поведение к разряду социальной нормы (Измены ... , 2015: Электронный ресурс).

Наши данные свидетельствуют о том же. Супружеская верность в восприятии студентов является ярко выраженной социальной нормой. Она важна, хотя и в различной степени, практически для всех студентов (очень важна - 78\%, скорее важна $19 \%$ ). Обратим внимание на то, что почти каждый пятый респондент занимает неопределенную позицию. Религиозный фактор в данном случае отразился на степени важности супружеской верности. Скорее важной она представляется 22\% в группах неверующих и нерелигиозных, 16\% православных и 3\% мусульман, тогда как очень важной ее считают $69 \%$ неверующих, 72\% нерелигиозных, 82\% православных и 97\% мусульман. Свободных взглядов на супружескую верность придерживаются 10\% неверующих, $6 \%$ нерелигиозных и $1 \%$ православных.

\section{ОТНОШЕНИЕ К АЕГААИЗАЦИИ ОАНОПОАЫХ БРАКОВ}

Аиберализация половой морали в России не отразилась на отношении к однополой любви. Мониторинговые исследования ВЦИОМ показывают, что неприятие гомосексуальных связей в российском обществе возрастает. Так, в период 1991-2016 гг. оно усилилось с 71 до 81\% (Навстречу ..., 2016: Электронный ресурс). Такое отношение к однополой любви значительно отличается от большинства стран западной цивилизации, в которых она стала социальной нормой, получив не только одобрение общественного мнения, но и закрепление в праве (Тихомиров, 2015). Причем на Западе либерализация половой морали размывает ценностно-нормативные структуры различных возрастных групп, особенно молодых, в том числе и религиозных (Тихомиров, 2016). Так, например, онлайн-опрос почти 10 тыс. католиков, проведенный Союзом католической молодежи Германии в 2013 г., показал, что большинство молодых людей поддерживают идею церковного венчания однополых пар (9 из 10 ..., 2014: Электронный ресурс).

В России же ситуация иная. Результаты нашего исследования 2016 г. показали, что нетрадиционные сексуальные отношения воспринимаются студентами как ярко выраженная девиация. Три четверти опрошенных полагают, что в России не стоит узаконивать однополые браки (59\% определенно против и $15 \%$ скорее против) и только $15 \%$ придерживаются противоположного мнения (7\% однозначно одобряют эту идею, а еще $8 \%$ скорее одобряют). Ключевым фактором, определяющим дифференци- 
ацию отношения к легализации однополых браков, является религиозный. Позиция православных и мусульман практически совпадает и значительно отличается от гораздо более либеральной позиции нерелигиозных и неверующих студентов. Так, если среди религиозных респондентов одобряют эту идею не более $8 \%$, то среди нерелигиозных - 22\%, а среди неверующих - уже $30 \%$ (табл. 3).

Различия в отношении однополых браков проявились и в гендерном аспекте, особенно в части их неодобрения. Так, либеральной позиции придерживаются 16\% девушек (определенно за эту идею высказались 7\%) и 10\% юношей (5\%), а традиционной $69 \%$ девушек (определенно против этой идеи - 51\%) и 83\% юношей $(74 \%)$. Причем примерно каждый шестой юноша (чего практически не было у девушек) в анкете старался всячески маркировать (усиленным выделением) негативное отношение к однополой любви, иногда сопровождая свою позицию нелицеприятными комментариями в адрес гомосексуалистов.

\section{ЗАКАЮЧЕНИЕ}

Религиозный ренессанс, хотя и не смог блокировать развертывание либерализации половой морали в России, не дал этой либерализации окончательно разрушить традиционную нравственную систему. Тем не менее деструкция нормативности в вопросах половой морали глубоко проникла в российское общество, что отражается в мировоззрении большинства студентов. Исключение составляют некоторые группы религиозных студентов.

Религия, как еще раз показали результаты эмпирического исследования, оказывает значительное влияние на формирование традиционных ценностно-нормативных представлений в семейно-брачной сфере. Но исследование внесло и уточнения. Наиболее выражены традиционные взгляды на семью и половую мораль у религиозных студентов, наименее - у неверующих. В большей или меньшей степени это проявляется как в жизненных установках, так и в отношении к добрачному целомудрию, сожительству, разводу, адюльтеру, гомосексуализму. Но и позиция религиозных студентов, прежде всего по вопросам добрачных сексуальных отношений, неодинакова. Она определяется конфессиональной принадлежностью: мусульмане занимают гораздо более традиционную позицию в вопросах половой морали, нежели православные,

Таблица 3

ОТНОШЕНИЕ СТУАЕНТОВ К АЕГААИЗАЦИИ ОАНОПОАЫХ БРАКОВ В РОССИИ В ЗАВИСИМОСТИ ОТ ИХ РЕАИГИОЗНОЙ ПРИНАААЕЖНОСТИ, \%

Table 3

THE ATTITUDE OF STUDENTS TO THE LEGALIZATION OF SAME-SEX MARRIAGES IN RUSSIA DEPENDING ON THEIR RELIGION, IN \%

\begin{tabular}{|l|c|c|c|c|}
\hline \multirow{2}{*}{$\begin{array}{c}\text { Надо ли легализовать } \\
\text { одополье браки } \\
\text { в России? }\end{array}$} & \multicolumn{4}{|c|}{ Религиозная принадлежность } \\
\cline { 2 - 5 } & православнье & мусульмане & нерелигиознье & атеистьь \\
\hline Определенно да & 3 & 3 & 10 & 15 \\
Скорее да & 5 & 3 & 12 & 15 \\
Скорее нет & 11 & 7 & 22 & 24 \\
Определенно нет & 69 & 70 & 43 & 44 \\
Затрудняюсь ответить & 12 & 17 & 13 & 2 \\
\hline
\end{tabular}


за исключением группы воцерковленных, но ее численность составляет всего несколько процентов.

Итак, отношение к добрачному целомудрию и сожительству как норме или отклонению определяется не только религиозной принадлежностью, но и уровнем религиозности молодежи. Однако в целом большинство православных нормально относятся к этим явлениям и не видят в них ничего предосудительного, чего нельзя сказать о мусульманах. Соответственно, для православных, хотя и в гораздо меньшей степени, чем для нерелигиозных и неверующих студентов, характерна деструкция нормативности в вопросах половой морали.

\section{СПИСОК АИТЕРАТУРЫ}

Концепция государственной семейной политики в Российской Федерации до 2025 года (2014) [Электронный ресурс] // Российская газета. 29 августа. URL: https://rg.ru/2014/08/29/ semya-site-dok.html (дата обращения: 02.12.2016).

Указ Президента Российской Федерации от 09.10.2007 г. № 1351 «Об утверждении Концепции демографической политики Российской Федерации до 2025 года» (2007) [Электронный ресурс]// Президент России. URL: http://www.kremlin.ru/acts/bank/26299 (дата обращения: 02.12.2016).

9 из 10 молодых католиков в Германии игнорируют учение Церкви о половых отношениях (2014) [Электронный ресурс]// Katolik.ru. 06 января. URL: http://www.katolik.ru/mir/117756-9iz-10-molodykh-katolikov-v-germanii-ignoriruyut-uchenie-tserkvi-o-polovykh-otnosheniyakh.html (дата обращения: 02.12.2016).

Брак, дети, супружеские измены: сейчас и 25 лет назад (2015) [Электронный ресурс] // ВЦИОМ. Пресс-выпуск №2771. 10 февраля. URL: https://wciom.ru/index.php?id=236\&uid= 115142 (дата обращения: 02.12.2016).

Вот какие мы - россияне. Об итогах Всероссийской переписи населения 2010 года (2011) [Электронный ресурс] // Российская газета. Федеральный выпуск №5660 (284). 22 декабря. URL: https://rg.ru/2011/12/16/stat.html (дата обращения: 02.12.2016).

Аобрачный секс: табу или норма? (2015) [Электронный ресурс] // ВЦИОМ. Пресс-выпуск № 2863. 26 июня. URL: https://wciom.ru/index.php?id=236\&uid=115299 (дата обращения: 02.12.2016).

Измены: табу или норма (2015) [Электронный ресурс] // Иевада-Центр. 19 февраля. URL: http://www.levada.ru/2015/02/19/izmeny-tabu-ili-norma/ (дата обращения: 02.12.2016).

Кон, И. С. (2005) Сексуальная культура в России. Клубничка на березке. 2-е изд. М. : Айриспресс. 437 с.

Ауков, В. А., Тихомиров, А. А. (2012) Аобрачные сексуальные отношения молодежи: дилемма социальной нормы и отклонения. М. : Изд-во Моск. гуманит. ун-та. 188 с.

Микроперепись населения 2015 (2015) [Электронный ресурс]// Федеральная служба государственной статистики. URL: http://www.gks.ru/free_doc/new_site/population/demo/microperepis/finish/micro-perepis.html (дата обращения: 02.12.2016).

Навстречу Аню святого Валентина: о любви по-взрослому (2016) [Электронный ресурс] // ВЦИОМ. 12 февраля. URL: http://wciom.ru/index.php?id=236\&uid=115581 (дата обращения: 02.12.2016).

Осипова, И. (2013) Гражданские браки: смыслы и отношение [Электронный ресурс]// ФОМ. 21 сентября. URL: http://fom.ru/blogs/11093 (дата обращения: 02.12.2016).

O разводах (2013) [Электронный ресурс] // ФОМ. 10 января. URL: http://fom.ru/rabota-i$\mathrm{dom} / 10769$ (дата обращения: 02.12.2016).

O разводах 25 лет назад и сегодня (2015) [Электронный ресурс]// ВЦИOM. 07 июля. URL: http://wciom.ru/index.php?id=236\&uid=115312 (дата обращения: 02.12.2016).

O семье и браке (2000) [Электронный ресурс]// ВЦИОМ. 25 июня. URL: http://wciom.ru/ index.php?id=236\&uid=479 (дата обращения: 02.12.2016).

Россия в цифрах. 2016: Крат. стат. сб. (2016). М. : Росстат. 543 с. 
Тихомиров, А. А. (2017) Религиозное сознание и поведение московских студентов: тезаурусный подход// Тезаурусы и тезаурусная сфера : II Академические чтения памяти Владимира Андреевича Аукова, 29 марта 2017 г. : сб. науч. трудов / редкол. : Вал. А. Ауков (отв. ред.), Н. В. Захаров, Т. Ф. Кузнецова, Ч. К. Аамажаа, В. П. Трыков. М. : Изд-во Моск. гуманит. ун-та. 256 с. C. $198-209$.

Тихомиров, А. А. (2009) Аобрачные сожительства в Москве как новая составляющая матримониального поведения молодежи // Знание. Понимание. Умение. № 3. С. 106-110.

Тихомиров, А. А. (2015) Аиберализация половой морали в современном мире // Знание. Понимание Умение. № 3. C. 93-108. DOI: 10.17805/zpu.2015.3.8

Тихомиров, А. А. (2016) Кризис религиозности и проблема либерализации половой морали в современной западной цивилизации // Знание. Понимание Умение. №1. C. 104-117. DOI: 10.17805/zpu.2016.1.8

Чеснокова, В. Ф. (2005) Тесным путем. Процесс воцерковления населения России в конце XX века. М. : Академический проект. 304 с.

Аата поступления: 18.01.2017 2.

SEXUAL MORALITY OF MOSCOW STUDENTS: THE RELIGIOUS ASPECT

\section{A. TIKHOMIROV}

PLEKHANOV RUSSIAN UNIVERSITY OF ECONOMICS

The article is based on the results of the author's empirical research conducted in 2016. It examines the influence of religion on family values and sexual morality of Moscow students who consider themselves followers of one or another religion. The author makes a differentiation of how the relationship of religious (Orthodox Christians and Muslims), non-religious and non-believing students treat large families, premarital chastity, cohabitation, divorce, adultery, and same-sex marriages. The perception of these phenomena varies both between religious, non-religious, and non-believing groups, and within religious groups. Religious students demonstrate more traditional views on family and sexual morality, while non-believing students' views are less prominent. Among the religious students Muslims adopt a more traditional attitude in matters of sexual morality, compared to the Orthodox, except for a group of churched Christians, but their numbers are insignificant ( $4 \%$ of those who call themselves Orthodox). The author shows that the attitude towards the above indicated aspects of family and marriage as a norm or deviation is determined not only by religious affiliation, but also by the level of the religiousness of the youth. However, in general, the Orthodox are characterized by the destruction of normality in various matters of sexual morality although to a much lesser extent than for the non-religious and non-believing students.

The liberalization of sexual morality in Russia has hardly affected the sphere of non-traditional sexual relations. Most students in Moscow, especially religious ones, perceive same-sex relationships as a prominent deviation.

Keywords: sexual morality; religiousness; the Orthodox; the Muslim; students; values; chastity; cohabitation; same-sex marriages

\section{REFERENCES}

Kontseptsiia gosudarstvennoi semeinoi politiki v Rossiiskoi Federatsii do 2025 goda (2014). Rossiiskaia gazeta, 29 August [online] Available at: https://rg.ru/2014/08/29/semya-site-dok.html (access date: 02.12.2016). (In Russ.).

Ukaz Prezidenta Rossiiskoi Federatsii ot 09.10.2007 g. № 1351 «Ob utverzhdenii Kontseptsii demograficheskoi politiki Rossiiskoi Federatsii do 2025 goda» (2007). Prezident Rossii [online] Available at: http://www.kremlin.ru/acts/bank/26299 (access date: 02.12.2016). (In Russ.).

9 iz 10 molodykh katolikov v Germanii ignoriruiut uchenie Tserkvi o polovykh otnosheniiakh (2014). Katolik.ru, 6 January [online] Available at: http://www.katolik.ru/mir/117756-9-iz-10-molodykh-katolikov-v-germanii-ignoriruyut-uchenie-tserkvi-o-polovykh-otnosheniyakh.html (access date: 02.12.2016). (In Russ.). 
Brak, deti, supruzheskie izmeny: seichas i 25 let nazad (2015). VT SIOM. Press-vypusk, no. 2771, 10 February [online] Available at: https://wciom.ru/index.php?id=236\&uid=115142 (access date: 02.12.2016). (In Russ.).

Vot kakie my - rossiiane. Ob itogakh Vserossiiskoi perepisi naseleniia 2010 goda (2011). Rossiiskaia gazeta, no. 5660 (284), 22 December [online] Available at: https://rg.ru/2011/12/16/stat. html (access date: 02.12.2016). (In Russ.).

Dobrachnyi seks: tabu ili norma? (2015). VTsIOM. Press-vypusk, no. 2863, 26 June [online] Available at: https://wciom.ru/index.php?id=236\&uid=115299 (access date: 02.12.2016). (In Russ.).

Izmeny: tabu ili norma (2015). Levada-Tsentr, 19 February [online] Available at: http://www.levada.ru/2015/02/19/izmeny-tabu-ili-norma/ (access data: 02.12.2016). (In Russ.).

Kon, I. S. (2005) Seksual' naia kul'tura v Rossii. Klubnichka na berezke. 2nd ed. Moscow, Airispress. 437 p. (In Russ.).

Lukov, V. A. and Tikhomirov, D. A. (2012) Dobrachnye seksual'nye otnosheniia molodezhi: dilemma sotsial' noi normy $i$ otkloneniia. Moscow, Izd-vo Mosk. gumanit. un-ta. 188 p. (In Russ.).

Mikroperepis' naseleniia 2015 (2015). Federal' naia sluzbba gosudarstvennoi statistiki [online] Available at: http://www.gks.ru/free_doc/new_site/population/demo/micro-perepis/finish/microperepis.html (access date: 02.12.2016). (In Russ.).

Navstrechu Dniu sviatogo Valentina: o liubvi po-vzroslomu (2016). VTsIOM, 12 February [online] Available at: http://wciom.ru/index.php?id=236\&uid=115581 (access date: 02.12.2016). (In Russ.).

Osipova, I. (2013) Grazhdanskie braki: smysly i otnoshenie. FOM, 21 September [online] Available at: http://fom.ru/blogs/11093 (access data: 02.12.2016). (In Russ.).

O razvodakh (2013). FOM, 10 January [online] Available at: http://fom.ru/rabota-i-dom/10769 (access date: 02.12.2016). (In Russ.).

O razvodakh 25 let nazad i segodnia (2015). VTsIOM, 7 Jule [online] Available at: http://wciom. $\mathrm{ru} /$ index.php? $\mathrm{id}=236 \&$ uid=115312 (access date: 02.12.2016). (In Russ.).

O sem'e i brake (2000). VTsIOM, 25 June [online] Available at: http://wciom.ru/index.php?id= 236\&uid=479 (access date: 02.12.2016). (In Russ.).

Rossiia v tsifrakh. 2016: Krat. stat. sb. (2016). Moscow, Rosstat. 543 p. (In Russ.).

Tikhomirov, D. A. (2017) Religioznoe soznanie i povedenie moskovskikh studentov: tezaurusnyi podkhod. In: Tezaurusy $i$ tezaurusnaia sfera : II Akademicheskie chteniia pamiati Vladimira Andreevicha Lukova, 29 marta 2017 g. : sb. nauch. trudov, Val. A. Lukov et al. (eds.). Moscow, Izd-vo Mosk. gumanit. un-ta. 256 p. Pp. 198-209. (In Russ.).

Tikhomirov, D. A. (2009) Dobrachnye sozhitel'stva v Moskve kak novaia sostavliaiushchaia matrimonial'nogo povedeniia molodezhi. Znanie. Ponimanie. Umenie, no. 3, pp. 106-110. (In Russ.).

Tikhomirov, D. A. (2015) Liberalizatsiia polovoi morali v sovremennom mire. Znanie. Ponimanie Umenie, no. 3, pp. 93-108. DOI: 10.17805/zpu.2015.3.8 (In Russ.).

Tikhomirov, D. A. (2016) Krizis religioznosti i problema liberalizatsii polovoi morali v sovremennoi zapadnoi tsivilizatsii. Znanie. Ponimanie Umenie, no. 1, pp. 104-117. DOI: 10.17805/zpu.2016.1.8 (In Russ.).

Chesnokova, V. F. (2005) Tesnym putem. Protsess votserkovleniia naseleniia Rossii $v$ kontse XX veka. Moscow, Akademicheskii proekt. 304 p. (In Russ.).

Submission date: 18.01.2017.

Амитрий Андреевич Тихомиров - кандидат социологических наук, доцент кафедры политологии и социологии Российского экономического университета им. Г. В. Плеханова. Адрес: 117997, Россия, г. Москва, Стремянный пер., 28, корп. 1. Тел.: +7 (495) 958-23-27. Эл. адрес: dat1983@yandex.ru

Tikhomirov Dmitry Andreevich, Candidate of Sociology, Associate Professor, Department of Political Science and Sociology, Plekhanov Russian University of Economics. Postal address: 28 Bldg. 1, Stremyannyi Lane, Moscow, Russian Federation 117997. Tel.: +7 (495) 958-23-27. E-mail: dat 1983@yandex.ru 